\title{
Stimulation by Voluntary Exercise of Adrenal Glucocorticoid Secretion in Mature Female Hamsters
}

\author{
KATARINA T. BORER, ${ }^{*} \ddagger^{1}$ LORELLE L. BESTERVELT, $\dagger$ MICHAL MANNHEIM, $*$ \\ MARY BETH BROSAMER,* MELVA THOMPSON,* UMA SWAMY* AND W. N. PIPER \\ Departments of *Movement Science, $\nmid$ Environmental and Industrial Health, Pharmacology, and $\ddagger$ Reproductive \\ Sciences Program, The University of Michigan, Ann Arbor, MI 48109-2214
}

Received 24 January 1991

\begin{abstract}
BORER, K. T., L. L. BESTERVELT, M. MANNHEIM, M. B. BROSAMER, M. THOMPSON, U. SWAMY AND W. N. PIPER. Stimulation by voluntary exercise of adrenal glucocorticoid secretion in mature female hamsters. PHYSIOL BEHAV 51(4) 713-718, 1992.- The possibility that habitual voluntary running induces a chronic change in adrenal glucocorticoid synthesis and secretion was examined in freely running mature female hamsters, in whom this behavior accelerates growth, reduces body fat levels, and elevates core temperature. Hamsters were free to run on horizontal discs or in vertical wheels between 32 and 80 days, in 14L:10D or in 10L:14D photoperiods, and at the end of this period, corticosterone and cortisol steroidogenesis and serial plasma corticosterone concentrations during day and night were used as measures of the chronic stimulation of adrenal cortical activity. Habitual voluntary running significantly increased steroidogenesis of both glucocorticoids and plasma corticosterone concentrations and alone accounted for all the variance in enhanced synthesis and secretion of corticosterone. Acute exercise and/or the nocturnal phase of circadian period enhanced the chronic stimulatory effects of exercise on cortisol. Despite its voluntary and apparently stress-free nature, running induces chronic increases in basal glucocorticoid secretion in mature female hamsters. Putative oversecretion of corticotropin releasing factor in freely running hamsters could account for increased steroidogenesis, acceleration of growth, reduced body fat levels, and core temperature elevation.
\end{abstract}

Corticosterone Cortisol Stress Rhythm

GLUCOCORTICOID hormones have multiple biological functions: they inhibit growth, control energy metabolism, and affect immune responses. Further, exercise stimulates glucocorticoid secretion in many mammalian species.

Glucocorticoids suppress growth by central and peripheral actions. They inhibit growth hormone secretion (25) by increasing the somatostatin ( 31$)$ and by decreasing the growth hormone releasing hormone concentration $(16,42)$ in the hypothalamus. In the peripheral tissues, they suppress growth by inhibiting somatomedin synthesis (29) and by promoting cellular differentiation (22).

Glucocorticoids raise blood glucose concentration by stimulating gluconeogenesis (38) and, more slowly, promote release of blood lipids by lipolysis (2) in circumstances of energy shortage. In physiological concentrations glucocorticoids stimulate immune responses, while in pharmacological doses they suppress them (30).

Exercise affects glucocorticoid secretion in several species of mammals and man. Hormone synthesis and release is acutely stimulated in man $(10,18,24,36)$ and $\operatorname{dog}(35)$ when exercise exceeds the intensity of about $90 \%$ of the maximal aerobic ca- pacity, or when the duration of submaximal exercise is extended to the state of exhaustion $(14,19,26,35,39)$.

In this study we ask whether habitual voluntary running in mature hamsters leads to an alteration in glucocorticoid synthesis and release. The question is of interest because habitual voluntary running in mature hamsters produces neuroendocrine, metabolic, and core temperature changes which could in part be caused by altered glucocorticoid secretion.

In the hamster, voluntary running of greater than one week's duration accelerates somatic and skeletal growth $(3,6)$ and leads to a doubling of basal growth hormone $(\mathrm{GH})$ pulse amplitude and frequency (8). Endogenous opioids (8) appear to mediate exercise-induced increase in basal pulsatile $\mathrm{GH}$ secretion by suppressing endogenous somatostatin release or action. One would predict diminished glucocorticoid secretion or action in exercising hamsters if these steroids played a role in exerciseinduced growth acceleration.

A modest $10-20 \%$ increase in food consumption occurs in running hamsters after a 1 week delay (3) and appears inadequate to support accelerated somatic growth $(3,6)$. Consequently the body fat stores of running hamsters decrease during several weeks

\footnotetext{
${ }^{1}$ Requests for reprints should be addressed to Dr. Katarina T. Borer, Division of Kinesiology, University of Michigan, Ann Arbor, MI 48109-2214.
} 
of running (40). One would predict increased secretion or action of glucocorticoid hormones if they played a role in exerciseinduced lipolysis.

Exercise-induced elevation of core temperature, both during the night when hamsters engage in running and during the day when animals are quiescent, also occurs after a week of running, and is most likely a manifestation of an activated immune system (11). If glucocorticoids were involved in this phenomenon, we would predict their increased secretion or action.

Finally, it is not clear whether the voluntary and presumably stress-free running behavior can have an effect on glucocorticoid release. To evaluate a possible glucocorticoid involvement in the neuroendocrine and metabolic adaptations to habitual voluntary running, we hypothesized that running in mature hamsters chronically alters the synthesis and release of glucocorticoid hormones. We tested the hypothesis by comparing exercising and sedentary hamsters for (i) the activities of glucocorticoid biosynthetic enzymes, and (ii) the nycthemeral secretory pattern of corticosterone, one of the two glucocorticoids synthesized by this species $(1,13,17.20,21,32)$.

\section{MATERIALS AND METHODS}

\section{Animals}

Female hamsters were obtained from the breeder (Harlan Sprague-Dawley Laboratory Animals, Haslett, MI) at the age of about 90 days. Hamsters were housed individually in acrylic boxes $21 \mathrm{~cm}$ long, $21 \mathrm{~cm}$ wide, and $20 \mathrm{~cm}$ high with wire floors when assigned to the sedentary condition, or in one of the two types of activity boxes when assigned to exercise. Animals were housed in temperature controlled rooms $\left(20-22^{\circ} \mathrm{C}\right)$ under different lighting schedules (Table 1). Formulab 5008 Purina chow pellets and water were available ad lib throughout the study. All three experiments were started in May.

\section{Experimental Design}

In each experiment, hamsters were matched by weight and assigned to exercise and sedentary groups. In each experiment the duration of running was longer than 7 days, the period necessary for induction of growth acceleration $(3,6)$, hyperphagia (3), and core temperature elevation (11).

Experiments 1 and 2 examined exercise-induced changes in the activities of biosynthetic enzymes for corticosterone and cortisol. Numbers of exercising and sedentary hamsters were, respectively, seven and six in Experiment 1 and nine and eight in Experiment 2.

Experiment 3 examined the effect of habitual exercise on the secretory pattern of corticosterone in nine exercising and five sedentary hamsters in the regular photoperiod, and eight exercising and five sedentary hamsters in the reversed photoperiod.

As the experiments also served for data collection in other studies, they differed in the photoperiod and activity devices (Table 1). Differences in the photoperiod and activity devices were unlikely to affect the results as the running distances and growth acceleration on either the activity disc or in the rotating wheel are similar (4), and the photoperiod length has no influence over exercise-induced growth acceleration (5).

\section{Running Activity}

In Experiments 1 and 3, acrylic boxes were used, $40 \mathrm{~cm}$ long, $30 \mathrm{~cm}$ wide, and $40 \mathrm{~cm}$ high, with wire floors and a freely turning horizontal disc, $25 \mathrm{~cm}$ in diameter $(3,4)$. In Experiment 2, hamsters lived in a metal box $25 \mathrm{~cm}$ long, $13 \mathrm{~cm}$ wide, and $15 \mathrm{~cm}$ high, with free access to a rotating vertical wheel, $11 \mathrm{~cm}$ wide,
TABLE 1

DIFFERENCES IN THE EXPERIMENTAL DESIGNOH THE THREE EXPERIMENTS

\begin{tabular}{|c|c|c|c|c|}
\hline & $\begin{array}{c}\text { Exercise } \\
\text { Duration } \\
\text { (days) }\end{array}$ & $\begin{array}{l}\text { Activity } \\
\text { Device }\end{array}$ & $\begin{array}{l}\text { Photoperiod } \\
\text { Length (h) }\end{array}$ & $\begin{array}{c}\text { Blood/tissue } \\
\text { Collection } \\
\text { Time (h) }\end{array}$ \\
\hline Experiment 1 & 32 & Disc & 14L:10ID* & $1030-1130$ \\
\hline Experiment 2 & 80 & Wheel & $10[\therefore 14 \mathrm{Dt}$ & $1030-1130$ \\
\hline \multicolumn{5}{|l|}{ Experiment 3} \\
\hline Regular phase* & 63 & Disc & 14L:10D* & $0900-1430$ \\
\hline Reverse phaset & 63 & Disc & 14L:10D† & $0900-1430$ \\
\hline
\end{tabular}

* Lights on at $0700 \mathrm{~h}$.

+ Lights on at $1700 \mathrm{~h}$.

with a circumference of $111 \mathrm{~cm}$ (Wahmann Manufacturing Co., Timonium, MD). Running activity was measured in revolutions per day (RPD) and converted to $\mathrm{km} /$ day from the functional $48-\mathrm{cm}$ circumference of the discs (4) and the $111-\mathrm{cm}$ circumference of the wheels.

\section{Adrenal Gland and Blood Collection}

Animals were killed by decapitation between $1030 \mathrm{~h}$ and $1130 \mathrm{~h}$ to collect adrenal glands. Adrenal glands were removed within $1 \mathrm{~min}$ of decapitation, cleaned of adhering fat, weighed. and kept chilled for the enzyme assays.

In Experiment 3, intracardiac polyethylene catheters (PE-50, Intramedic) were implanted through the right jugular vein (7) under pentobarbital anesthesia $(75 \mathrm{mg} / \mathrm{kg})$. Catheters were kept patent with heparinized saline $(200 \mathrm{U} / \mathrm{ml})$. Hamsters remained in home cages for $12-36 \mathrm{~h}$ after the cannulation. They were transferred to sedentary cages $12 \mathrm{~h}$ prior to blood collection. Blood $(0.5 \mathrm{ml})$ was collected every $20 \mathrm{~min}$ between $0900 \mathrm{~h}$ and $1430 \mathrm{~h}$ and for the hamsters maintained in reversed photoperiod, this was done under dim red lighting.

Blood cells in plasma samples were packed by centrifugation. washed, and used to make reconstituted blood that was reinfused in equal volumes after each blood removal (7). Plasma was stored at $-20^{\circ} \mathrm{C}$ for subsequent corticosterone assay.

\section{Glucocorticoid Enzyme Assays}

Since the newly synthesized glucocorticoids are secreted rather than stored by adrenals (21), we used the activities of 21 - and 17-hydroxylases as indices, respectively, of exercise-induced changes in corticosterone and in cortisol steroidogenesis and secretion.

Glucocorticoid biosynthesis entails conversion of cholesterol to progesterone via pregnenolone. Progesterone is converted to corticosterone through a biosynthetic pathway initially catalyzed by 21-hydroxylase, or to cortisol through the alternate pathway catalyzed by 17 -hydroxylase (21). For glucocorticoid enzyme assays, the adrenal glands from two animals were pooled. Tissue preparation and the 21 -hydroxylase (27) and 17-hydroxylase (28) enzyme activities were carried out according to the procedures previously described. The sensitivities of the 21 - and 17-hydroxylase assays were, respectively, $0.1 \mathrm{pmol}$ deoxycorticosterone per milligram per minute and $0.1 \mathrm{pmol} 17$-hydroxyprogesterone per milligram per minute.

\section{Corticosterone Assay}

To decide whether glucocorticoids other than corticosterone might interfere in the assay for plasma corticosterone in the 


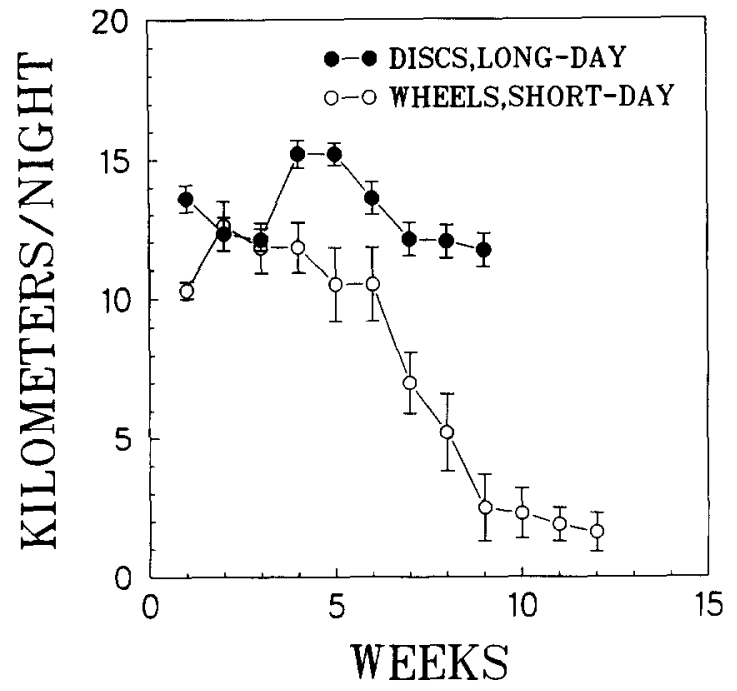

FIG. 1. Distances run are expressed in $\mathrm{km}$ per night and have been averaged for 1 -week blocks in 25 hamsters running on horizontal discs in 14L:10D photoperiod ( running in vertical wheels in 10L:14D photoperiod (O, Experiment 2).

hamster, sera from an adrenalectomized hamster and from four adrenal-intact hamsters were analyzed in the corticosterone assay with and without glucocorticoid extraction and corticosterone purification.

Glucocorticoids were extracted and corticosterone was purified as previously described (34). The purified steroid was scraped from the silica chromatography plate and solubilized in $1 \mathrm{ml}$ of absolute ethanol and stored at $-20^{\circ} \mathrm{C}$ for subsequent corticosterone assay.

A corticosterone radioimmunoassay (RIA) kit for rats and mice (Radioassay Systems Laboratories, Carson, CA) was used for determination of corticosterone in hamster plasma. Ten $\mu \mathrm{l}$ of plasma were diluted 1:200 and used in duplicate. Assay entailed the use of ${ }^{125} \mathrm{I}$-corticosterone and an antibody specific to rodent corticosterone with less than $1 \%$ crossreactivity with glucocorticoids, mineralocorticoids, and sex steroids.

\section{Data Analyses}

Single measurement data were analyzed with student's $t$-test for two independent groups or with $2 \times 2$ ANOVA for four groups. Changes with time in body weight and in the sequential blood corticosterone values were analyzed with univariate repeated measures ANOVA. Since pooling of adrenals from two animals required pooling of enzyme data from Experiments 1 and $2,2 \times 2$ ANOVA was run to assess the possible contribution of experimental differences to experimental outcome. Data variability is expressed throughout in SEMs.

\section{RESULTS}

\section{Running Activity}

Activity levels averaged for 1-week blocks of time are shown in Fig. 1. In the long photoperiod, hamsters maintained stable activity levels of about $12.5 \mathrm{~km}$ per night (25,000 RPD) throughout the 5 (Experiment 1 ) or 9 weeks (Experiment 3) of exposure to exercise. In the short photoperiod, hamsters ran about $11 \mathrm{~km}$ per night (10,000 RPD) during the first 6 weeks. Voluntary activity declined between the 6 th and 9 th week to

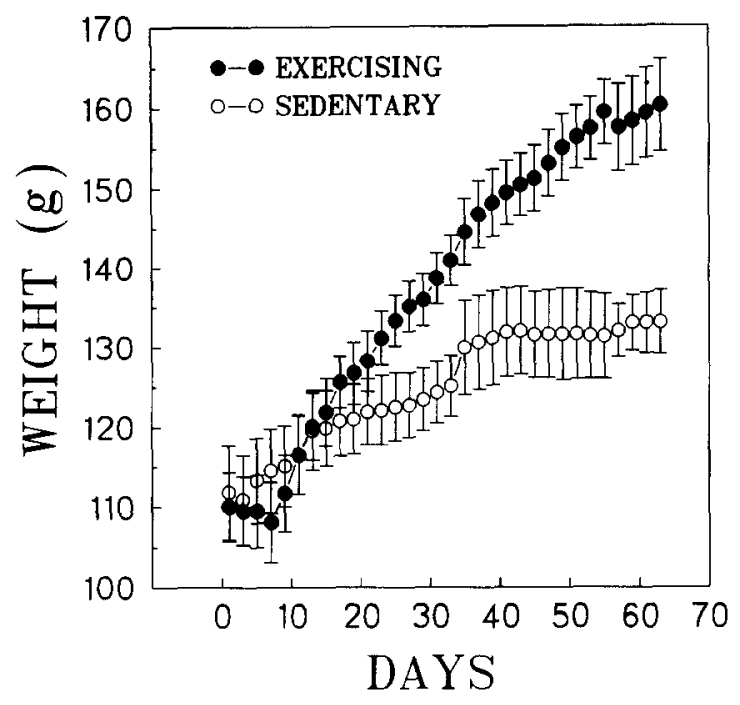

FIG. 2. Weight changes of 25 exercising $(\bullet)$ and 16 sedentary $(O)$ hamsters maintained in 14L:10D photoperiod in Experiments 1 and 3.

one-eighth of the starting level and remained significantly lower $(p<0.05)$ through the 12 th week of exercise, as was previously shown in hamsters maintained in short photoperiods (43).

\section{Growth}

Exercise consistently increased the rate of weight gain in all experiments. For the corresponding periods of exercise in Experiments 1 and 3, shown in Fig. 2, exercise interacted significantly with time $[\mathrm{F}(1,17)=14.938, p<0.001]$ to produce greater weight gains (Fig. 2). Exercise alone $[\mathrm{F}(1,78)=9.735, p<0.005]$ and in interaction with time $[\mathrm{F}(78)=12.867, p<0.001]$ resulted in significant increase in weight gain in hamsters from Experiment 2 (Fig. 3). Exercise-induced acceleration of ponderal growth was expressed 11 days earlier in hamsters exercising in the long photoperiod [after day $25, t(39)=2.046, p<0.05$ ] than in hamsters running in the short photoperiod (after day $34, t(17)=$ $4.73, p<0.05$ ).

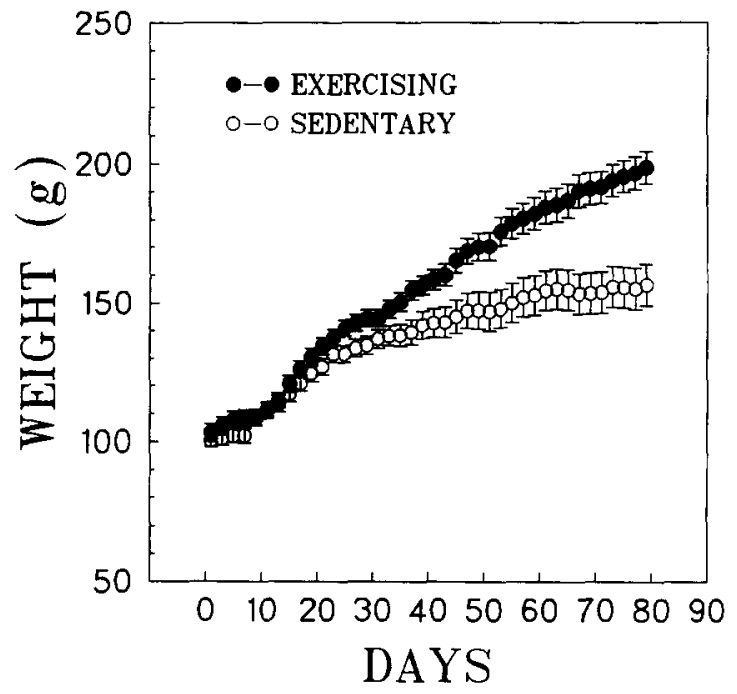

FIG. 3. Weight changes of 11 exercising $(\Theta)$ and 8 sedentary $(O)$ hamsters maintained in 10L:14D photoperiod in Experiment 2. 
TABLE 2

ADRENAL WEIGHTS AND ACTIVITIES OF THE BIOSYNTHETIC ENZYMES FOR CORTICOSTERONE (21-HYDROXYLASE) AND CORTISOL (17-HYDROXYLASE)

\begin{tabular}{|c|c|c|}
\hline & Exereising & Sedentary \\
\hline \multicolumn{3}{|l|}{ Adrenal glands } \\
\hline Experiment $1(\mathrm{~g})$ & $23.06 \pm 2.26 * \$$ & $17.78 \pm 1.31 \$$ \\
\hline Experiment $2(\mathrm{~g})$ & $27.90 \pm 1.66^{*}$ & $20.48 \pm 0.73$ \\
\hline Experiment $1(\mathrm{~g} / 100 \mathrm{~g})$ & $17.17 \pm 1.66$ & $14.97 \pm 1.26$ \\
\hline Experiment $2(\mathrm{~g} / 100 \mathrm{~g})$ & $14.56 \pm 0.89$ & $13.90 \pm 0.45$ \\
\hline \multicolumn{3}{|c|}{$\begin{array}{l}\text { Enzyme activities }\left(\mathrm{pmol} \cdot \mathrm{mg}^{-1}\right. \\
\text { protein } \cdot \min 1)\end{array}$} \\
\hline 21-Hydroxylase & $305.0 \pm 19.0 \dagger$ & $118.0 \pm 7.0$ \\
\hline 17-Hydroxvlase & $311.2 \pm 82.5 \ddagger$ & $74.0 \pm 17.8$ \\
\hline
\end{tabular}

${ }^{*}+\ddagger$ Significant effects of exercise: $* \mathrm{~F}(1,26)=15.557 . p<0.001: \dagger \mathrm{t}(8)$ $=9.11, p<0.05 ; \ddagger \mathrm{t}(9)=2.56, p<0.05$.

$\S$ Significant effects of experiment: $\mathrm{F}(1.26)=5.477, p<0.05$.

\section{Adrenal Weights}

Bilateral adrenal weights of exercising hamsters in Experiments 1 and 2 were significantly greater than those of sedentary hamsters (Table 2). This difference was abolished when the adrenal weights were normalized for body weight.

\section{Glucocorticoid Steroidogenesis}

Exercise significantly increased the activities of biosynthetic enzymes for both corticosterone (21-hydroxylase) and cortisol (17-hydroxylase, Table 2), and the change was somewhat greater for the 17-hydroxylase (4-fold) than for the 21-hydroxylase (2.6fold).

Only exercise contributed to the variance of 21 -hydroxylase values (exercise $F(1,6)=64.08, p<0.01$, experiment $F=0.289$. NS). By contrast, exercise had significantly greater effect on 17 hydroxylase activity in Experiment 2 (exercising, $421.3 \pm 69.1$; sedentary, $77.6 \pm 31.9 \mathrm{pmol} \cdot \mathrm{mg}^{-1} \cdot \mathrm{min}^{-1}$ than in Experiment 1 (exercising, $91.0 \pm 15$; sedentary, $68.5 \pm 9.5 \mathrm{pmol} \cdot \mathrm{mg}^{-1} \cdot \mathrm{min}^{-1}$ ). For 17-hydroxylase activity, there were significant effects of exercise $[F(1,6)=9.261, p<0.02]$; experiment $(F=7.952$, $p<0.03)$, and of their interaction $(\mathrm{F}=7.127, p<0.04)$.

\section{Plasma Conticosterone Concentrations}

The eight corticosterone assays that served for plasma hormone determinations in Experiment 3, had the following characteristics: specific binding was $62.2 \pm 3.4 \%$, intraassay coefficient of variation was $7 \%$, and the interassay coefficients of variation for the low- and high-corticosterone standard sera were $15.4 \%$ and $12 \%$, respectively. The limit of detection, defined as the standard curve intercept of one SEM of the buffer control tubes, was $2.0 \pm 0.7 \mathrm{ng} /$ tube. Assay sensitivity, defined as the standard curve intercept of two SD's of the buffer control tubes, was 5.2 $+1.5 \mathrm{ng} /$ tube.

There was no difference in the corticosterone values obtained from extracted $(15.4 \pm 11.4 \mathrm{ng} / \mathrm{ml})$ and unextracted $(16.1 \pm$ $12.0 \mathrm{ng} / \mathrm{ml}$ ) hamster plasma. Plasma corticosterone concentration for the combined nocturnal and diurnal periods was significantly higher in exercising than in sedentary hamsters [exercise, $\mathrm{F}(1,22)=6.783, p<0.02]$ and this difference was caused by the diurnal (Fig. 4) rather than the nocturnal (Fig. 5) phase of the photoperiod.

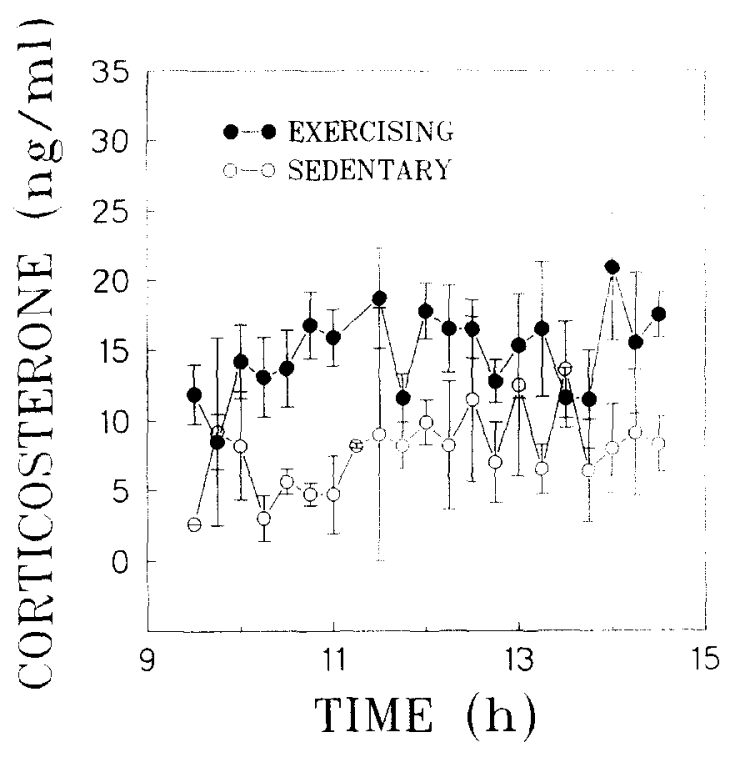

FIG. 4. Plasma corticosterone concentration measured in blood collected during the light phase of the $14 \mathrm{~L}: 10 \mathrm{D}$ photoperiod in 9 exercising and 5 sedentary hamsters in Experiment 3.

\section{DISCUSSION}

The principal finding of this study is that an extended period of voluntary running leads to enhanced glucocorticoid synthesis and release in hamsters (Table 2, Figs. 4 and 5). This effect was seen with different activity devices (Experiments $I$ and 2 ), with running exposures ranging between 32 days (Experiment 1) and 80 days (Experiment 2), with an eightfold difference in the nocturnal running rate (Experiments 1 and 2), and under variable photoperiod lengths (long in Experiments 1 and 3 and short in Experiment 2).

The observed neuroendocrine change was a chronic alteration in basal glucocorticoid synthesis and secretion rather than an

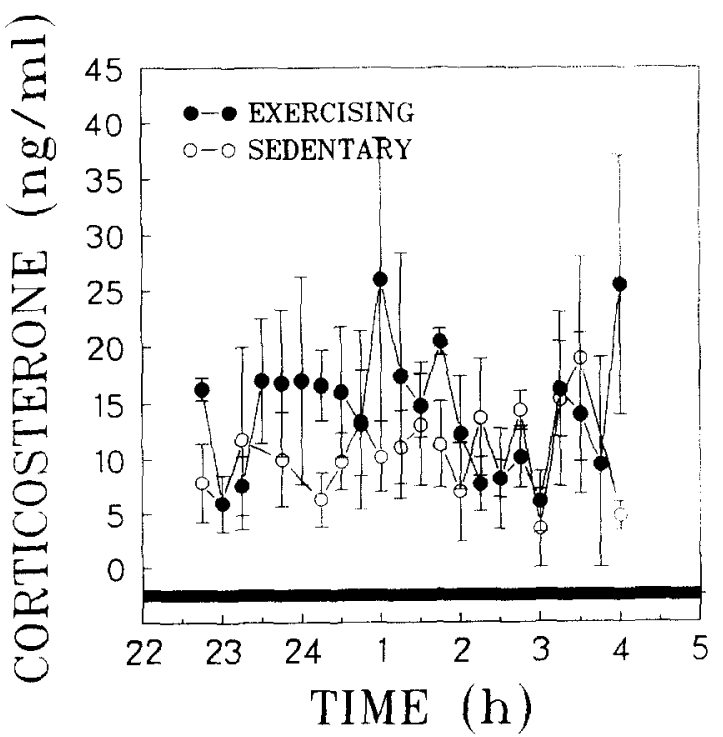

FIG. 5. Plasma corticosterone concentration measured in blood collected during the dark phase of the $14 \mathrm{~L}: 10 \mathrm{D}$ photoperiod in 8 exercising and 5 sedentary hamsters in Experiment 3. 
acute elicitation of hormone release during the act of running. Thus, increased steroidogenesis was evident at the times of day when hamsters were inactive (Experiment 1 and Fig. 4), in the short photoperiod that caused an eightfold reduction in the amount of running during the 6 weeks preceding hormone measurements (Table 2 and Fig. 1), and following cardiac catheterization that suppressed running and entailed $12 \mathrm{~h}$ of denied access to an activity disc (Experiment 3 ).

The distinguishing feature of the enhanced glucocorticoid steroidogenesis in exercising hamsters is that it is elicited by habitual, low-intensity, low-speed (4), and presumably stressfree voluntary running. Thus, the preferred speed of running in hamsters is between 35 and $51 \mathrm{~cm} \cdot \mathrm{s}^{-1}$ (4) or between 1.1 and $1.5 \mathrm{~km} \cdot \mathrm{h}^{-1}(9)$. This is about one-half to one-quarter the spontaneous speed of running displayed by rats, weasels, and whitefooted mice (4), about one-sixth of human jogging speed, and about one-twelfth of the running speed at intensities necessary for induction of chronic changes in basal glucocorticoid secretion in man (14). When motivated by electric shock (9), hamsters can generate about twice as much power while running on a treadmill as they do while running voluntarily. Thus the hamster is unusual among rodents for running spontaneously at about $50 \%$ of its maximal possible effort and for the extraordinary distances covered each day.

By contrast, only physical exercise that exceeds $90 \%$ of maximal effort $(14,19,26,36,39)$ and is extended to the point of exhaustion $(10,18,24,36)$ is effective in eliciting an acute glucocorticoid response in humans and dogs (35). Such acute glucocorticoid surge decays within minutes after the cessation of exercise. Chronic increases in basal glucocorticoid secretion analogous to those seen in this experiment can be induced in humans by prolonged, high-intensity $(15,23,36)$ but not submaximal intensity training.

The training effect in humans entails the capacity for oversecretion of both ACTH and cortisol in response to maximal physical effort $(14,23,36)$. Training also produces an oversecretion of cortisol in the unstimulated state unaccompanied by a change in ACTH secretion (23). This observation suggests that a change in adrenal sensitivity to ACTH may account for exercise-induced increases in basal glucocorticoid steroidogenesis. Since we have not measured ACTH levels in this study, we can only hypothesize that habitual running enhances adrenal glucocorticoid steroidogenesis through the stimulation of corticotropin releasing factor (CRF) and $\mathrm{ACTH}$, and not only through increased adrenal sensitivity to ACTH.

In contrast to equivalent exercise-induced elevations in corticosterone synthesis during day and night (Table 2), exercisestimulated cortisol biosynthesis was greater at night than during the daytime. We interpret this as the additive effects of the acute stimulus of nocturnal running, the nocturnal stimulation of cortisol biosynthesis $(1,13)$, and the chronic stimulation by habitual exercise of basal cortisol synthesis and release.

Corticosterone values obtained from cannulated hamsters were uniformly high during the light (Fig. 4) as well as dark (Fig. 5) phase of the photoperiod. The absence of a nycthemeral rhythm of glucocorticoid release $(1,13)$ indicates that our pro- cedures of cannulation and blood collection produced a significant degree of stress. Stimulatory effects of voluntary exercise in Experiment 3 therefore appear to be superimposed upon the acute stimulatory effects of stress.

The nature and pattern of changes in glucocorticoid synthesis and secretion in freely running hamsters prompt some general conclusions and speculations regarding their biological functions. First, habitual exercise in hamsters as in humans has the capacity to increase basal glucocorticoid synthesis and release $(14,23$, and this study).

The chronic nature of the change in glucocorticoid synthesis and secretion places it in the same category as the acceleration of growth $(6,8)$ and the elevation of core temperature (11) induced by habitual voluntary running in the hamster. All three phenomena represent changes in function set into operation by habitual voluntary running, maintained throughout the duration of this activity regime, and evident in the absence of the acute stimulus of exercise.

Simultaneous expression of exercise-induced oversecretion of growth hormone $(\mathrm{GH})(8)$ and of glucocorticoids (Table 2, Fig. 4) and of accelerated growth [Figs. 2, 3, and (6)], suggest that changes in adrenal steroidogenesis are not functionally related to changes in the control of growth. Glucocorticoid role in the control of growth is predominantly inhibitory $(22,25,29,31,43)$.

The most probable roles of chronic glucocorticoid oversecretion in spontaneously running hamsters is fuel mobilization and modulation of immune function. Freely running hamsters show progressive reduction in body fat content (40) at the same time as they show increased accumulation of lean body mass (6). Glucocorticoid and GH oversecretion are likely to act synergistically to induce lipolysis (2) and gluconeogenesis (38) and thus secure an adequate energy supply for the support of running and of protein biosynthesis.

Voluntary running induces chronic elevation in core temperature in female hamsters which is substitutive for fever induced by a pyrogen thus pointing to an exercise-induced activation of the immune system (11). Glucocorticoids $(12,30)$, as well as their hypothalamic precursor CRF $(37,41)$ appear to play an integral role in the activation and modulation of the immune responses.

Finally, voluntary running in the female hamster stimulates secretion or action of endogenous opioids (33), coreleased with ACTH in response to CRF stimulus, and the opiates, in turn, mediate exercise-induced growth hormone oversecretion (8). We suspect that voluntary running in hamsters stimulates CRF release or action which then directly, or through its endocrine progeny, accounts for the stimulation of the immune system and core temperature elevation (11), for increased $\mathrm{GH}$ secretion (8), and acceleration of somatic growth (6), and for increased glucocorticoid synthesis and release.

\section{ACKNOWLEDGEMENTS}

This study was supported in part by the National Science Foundation grants DCB85-02902 and DCB90-02998 to K.T.B

\section{REFERENCES}

1. Albers, H. E.; Yogev, L.; Todd, R. B.; Goldman, B. D. Adrenal glucocorticoids in hamsters: Role in circadian timing. Am. J. Physiol. 248:R434-R438; 1985.

2. Bierman, E. L.; Glomset, J. A. Disorders of lipid metabolism. In: Wilson, J. D.; Foster, D. W., eds. Williams textbook of endocrinology, 7th ed. Philadelphia: W. B. Saunders; 1985:1113.
3. Borer, K. T. Absence of weight regulation in exercising hamsters. Physiol. Behav. 12:589-597; 1974.

4. Borer, K. T. Characteristics of growth-inducing exercise. Physiol. Behav. 24:713-720; 1980

5. Borer, K. T.; Campbell, C. S.; Tabor, J.; Jorgenson, K.; Kandarian, S.; Gordon, L. Exercise reverses photoperiodic anestrus 
in golden hamsters. Biol. Reprod. 29:38-47: 1983.

6. Borer, K. T.; Kuhns, L. R. Radiographic evidence for acceleration of skeletal growth in adult hamsters by exercise. Growth $41: 1-13$; 1977.

7. Borer, K. T.: Kelch, R. P.; Corley, K. Hamster prolactin: Physiological changes in blood and pituitary concentrations as measured by a homologous radioimmunoassay. Neuroendocrinology $35: 13-$ 21: 1982 .

8. Borer, K. T.; Nicoski, D.; Owens, V. Alteration of the pulsatile growth hormone secretion by growth-inducing exercise: Involvement of endogenous opiates and somatostatin. Endocrinology 118:844-850: 1986.

9. Borer, K. T.: Potter, C. D.; Fileccia, N. Basis for the hypoactivity that accompanies rapid weight gain in hamsters. Physiol. Behav. 30: 389-397: 1983

10. Buono, M. J.; Yeager. J. E.; Hodgson, J. Plasma adrenocorticotropin and cortisol responses to brief high-intensity exercise in humans. $J$. Appl. Physiol. 61:1337-1339; 1986.

11. Conn, C. A.; Borer, K. T.; Kluger, M. J. Body temperature rhythm and response to pyrogen in exercising and sedentary hamsters. Med. Sci. Sports Exer. 22:636-642; 1990.

12. Del Rey, A.; Besedovsky, H.; Sorkin, E.; Dinarello, C. A. Interleukin1 and glucocorticoid hormones integrate an immunoregulatory feedback circuit. Ann. NY Acad. Sci. 496:85-90: 1987.

13. Donham, R. S.; Rollag, M. D.: Stetson. M. H. Daily rhythms of pituitary-ovarian function in the immature hamster are independent of adrenal and pineal influence. J. Rep. Fert. 83:809-818; 1988.

14. Farrell, P. A.; Garthwaite, T. L.; Gustafson. A. B. Plasma adrenocorticotropin and cortisol responses to submaximal and exhaustive exercise. J. Appl. Physiol. 55:1441-1444: 1983.

15. Farrell, P. A.: Kjaer, M.: Bach. F. W.; Galbo, H. Beta-endorphin and adrenocorticotropin response to supramaximal treadmill exercise in trained and untrained males. Acta Physiol. Scand. 130:617-625; 1987.

16. Fernandez-Durango, R.; Arimura, A.; Fishback, J.; Schally, A. V. Hypothalamic somatostatin and LHRH after hypophysectomy, in hyper- and hypothyroidism, and during anesthesia in rats. Proc. Soc. Exp. Biol. Med. 157:235-240; 1978.

17. Fraenkel, J. K.; Cook, K.; Grady, H. J.: Pendleton. S. K. Effects of hormones on adrenocortical secretion of golden hamsters. Lab Invest $14: 142-156: 1965$

18. Fraioli, F.; Moretti. C.; Paolucci, D.; Alicicco, E.; Crescenzi. F.; Fortunio. G. Physical exercise stimulates marked concomitant release of beta endorphin and adrenocorticotropic hormone in peripheral blood in man. Experientia 36:987-989: 1980

19. Galbo. H.: Richter, E. A.: Hilsted, J.: Holst, J. J.: Christensen, N. J.; Henrikson, J. Hormonal regulation during prolonged exercise. Ann. NY Acad. Sci. 301:72-80:1977.

20. Guerrier, D.; Thonnerieux, M.; Pellet, H. Dosage du cortisol et de la corticosterone dans le plasma et les surrenales de Hamster dore (Mesocricetus auratus). Compt. Rend. Acad. Sc. Paris 280:748-765: 1975

21. Kaplan, N. M. The adrenal glands. In: Griffin, J. E.; Ojeda, S. R., eds. Textbook of endocrine physiology. New York: Oxford University Press: 1988:245-272.

22. Knight, D. M.; Chapman, A. B.; Navre, M.; Drinkwater, L., Bruno J. J.; Ringold. G. M. Requirements for triggering of adipocyte differentiation by glucocorticoids and indomethacin. Molec. Endocrinol. 1:36-43; 1987.

23. Kraemer, W. J.: Fleck, S. J.: Callister, R.: Shealy, M.; Dudley, G. A Maresh. C. M.; Marchitelli, L.: Cruthirds, D.; Murray, T.; Falkel J. E. Training responses of plasma beta-endorphin, adrenocorticotropin, and cortisol. Med. Sci. Sports Exer. 21:146-153; 1989.

24. Kuoppasalmi. K.; Naveri. H.; Harkonen, M.; Adlerkreutz, H. Plasma cortisol. androstenedione. testosterone and luteinizing hormone in running exercise of different intensities. Scand $J$ ( Iin. Lab. Invest. 49:389-399: 1982

25. [ ocb. J. N. Corticosteroids and growth hormone. New Engl. J Med. 295:547-552: 1976.

26. Mathur, R. S.: Neff, M. R.: Landgrebe, S. C.: Moody. L. O.: Kirk. R. F:: Gadsden, R. H., Sr.: Rust, P. F. Time-related changes in the plasma concentrations of prolactin, gonadotropins. sex-hormone hinding globulin, and certain steroid hormones in female runners after a long-distance race. Fert. Ster, 46:1067-1070: 1986

27. Mebus, C. A.: Piper. W. N. Decreased rat adrenal 21-hydroxylase aclivity associated with decreased adrenal microsomal cytochrome P-450 after exposure to 2,3.7.8-tetrachlorodibenzo-n-dioxin. Biochem. Pharmacol. 35:4359-4362: 1986.

28. Mebus. C. A.; Reddy, V. R.; Piper. W. N. Depression of ral testicular 17-hydroxylase and 17,20-lyase after administration of 2,3,7,8-tetrachlorodibenzo- $p$-dioxin (TCDD). Biochem. Pharmacol. 36:727 $731: 1987$

29. Mosier, H. D.. Jr.; Jansons, R. A.; Hill, R. R.; Dearden, I. C. Cartilage sulfation and serum somatomedin in rats during and after cortisoneinduced growth arrest. Endocrinology 99:580-589; 1976.

30. Munck. A.: Guyre, P. M.; Holbrook. N. J. Physiological functions of glucocorticoids in stress and their relation to pharmacological actions. Endocrine Rev. 5:25-44; 1984.

31. Nakagawa, K.: Ishizuka, T.: Obara. T.: Matsubara, M.: Akikawa, $\mathrm{K}$. Dichotomic action of glucocorticoids on growth hormone secretion. Acta Endocrinol. 116:165-171: 1987.

32. Ottenweller. J. E.: Tapp. W. N.: Burke, J. M.; Natelson. B. H. Plasma cortisol and corticosterone concentrations in the golden hamster (Mesocricetus auratus). Life Sci. 37:1551-1558; 1985.

33. Potter, C. D.: Borer. K. T.: Katz. R. V. Opiate-receptor blockade reduces voluntary running but not self-stimulation in hamsters. Pharmacol. Physiol. Behav. 18:217-223:1983.

34. Quesenberry, R. O.: Ungar, F. Thin-layer chromatographic systems for adrenal corticosteroids. Anal. Biochem. 8:192-199: 1964.

35. Radosevich, P. M.: Nash. J. A.: Lacy, D. B.: O'Donovan. C.: Williams. P. E.: Abumrad. N. N. Effects of low- and high-intensity exercise on plasma and cerebrospinal fluid levels of ir-beta-endorphin. ACTH cortisol, norepinephrine, and glucose in the conscious dog. Brain Res. 498:89-98: 1989.

36. Rahkilia. P.; Hakala, E.: Alen, M.: Salminen, K.: Laatikainen. I Beta endorphin and corticotropin release is dependent on a threshoid intensity of running exercise in male endurance athletes. Life Sci. 43:551-558: 1988

37. Sapolsky, R.; Rivier, C.; Yamamoto, G.; Plotsky, P.; Vale, W. Interleukin-I stimulates the secretion of hypothalamic corticotropinreleasing factor. Science $238: 522-524 ; 1987$

38. Seitz. H. J.: Kaiser. M.; Krone, W.; Tarnovski, W. Physiological significance of glucocorticoids and insulin in the regulation of hepatic gluconeogenesis during starvation in the rat. Metabolism 25:1545$1555: 1976$

39. Tabata, 1.: Atomi, Y .: Miyashita, M. Blood glucose concentration dependent $\mathrm{ACTH}$ and cortisol responses to prolonged exercise. Clin. Physiol. 4:299-307; 1984.

40. Tsai. A. C.: Rosenberg. R.; Borer, K. T. Metabolic alterations induced by voluntary exercise and discontinuation of exercise in hamsters. Amer. J. Clin. Nutr. 35:943-949; 1982.

41. Uehara. A.; Gottschall, P. E.; Dahl, R. R.; Arimura. A. Adrenocorticotropin release induced by intracerebroventricular injection of recombinant human interleukin-1 in rats: Possible involvement of prostaglandin. Endocrinology 122:1773-1779; 1988.

42. Wehrenberg, W. B.; Baird, A.; Ling, N. Potent interaction between glucocorticoids and growth hormone-releasing factor in vivo. Science 221:556-558:1983.

43. Widmaier, E. P.: Campbell, C. S. Interaction of estradiol and photoperiod on activity patterns in the female hamster. Physiol. Behav. 24:923-930: 1980 . 